\title{
Exergy Analysis of VCR Systemwith Air-Cooled Condenser Working With Refrigerants R-134a \& Hydrocarbon
}

\author{
Naveen Kumar, DhirajJha
}

\begin{abstract}
This paper gives a detailed exergy analysis of a Vapour Compression Refrigeration System with the refrigerants $R-134 a$ and HC (mixture of R-290/R-600a). The aim of this paper is to find out the Exergy Analysis, Exergetic efficiency, Exergy Product, Exergy Destruction Ratio (EDR), Co-efficient of performance and $2^{\text {nd }}$ law efficiency for the main components of the system such as compressor, condenser, evaporator and expansion device (throttle valve). The objective of this work is to find out an exergy analysis of the Hydrocarbon refrigerant as an alternative for R-134a. The VCRS performance using R134a will be evaluated for the effect of evaporating temperature on COP, exergetic efficiency and EDR and then compared with Hydrocarbon refrigerant. Due to prevention of GWP (Global Warming Potential), Hydrocarbon and R-134a are used as refrigerants to give better result for domestic refrigerator operation $^{[8]}$.
\end{abstract}

Keywords --COP, EDR, EP, Exergetic loss,Exergic efficiency, Exergy Product, Hydrocarbon and R-134a.

\section{INTRODUCTION}

Among numerous refrigeration systems present in the market, the vapour compression refrigeration system was found to be an extremely suitable one in both commercial and domestic aspects. This isthe most useful \& reliable form of refrigeration system. In this device the refrigerantsused are R134a and Hydrocarbons (mixture of R290 \& R600a in equal ratio).The main objective of this paper is to find out an Exergy analysis of a VCR system havingair-cooled condenser under Hydrocarbon refrigerant as a substitute for $\mathrm{R}-134 \mathrm{a}$ on the working of a domestic refrigerator which is actually designed to work with R-134a.The performance of these two refrigerants was examined by an exergy analysis. The effect of evaporator temperature on the coefficient of performance, exergy loss, exergy efficiency and Exergy Destruction Ratio inmajor components of the system for R134a \&Hydrocarbons mixture is experimentally evaluated. Thesedays, maximumenergy is wasted for the purpose of cooling and air conditioning in both domestic and industrial fronts. However the refrigerants with the help of which cooling and air-conditioning are achieved have increased global warming and are reasons forozone layer depletion ${ }^{[8]}$.

Revised Manuscript Received on December 30, 2019.

* Correspondence Author

Naveen Kumar, Student of Mechanical Engineering, BIT Sindri, Dhanbad, India. Email: naveen.mesra@gmail.com

DhirajJha, Assistant Professor, Department of Mechanical Engineering, BIT Sindri, Dhanbad, India. Email: djha@bitsindri.ac.in

(C) The Authors. Published by Blue Eyes Intelligence Engineering and Sciences Publication (BEIESP). This is an open access article under the CC BY-NC-ND license (http://creativecommons.org/licenses/by-nc-nd/4.0/)
The prerequisiteof an ideal refrigerantis to possess good physical as well as chemical properties by which refrigerants should be non-toxic, non-flammable and have low boiling point. Chlorofluorocarbon (CFC) and HydroChlorofluorocarbons (HCFCs) have been used over the last many decades and they contain large number of chlorine atoms with them. Also these refrigerants are responsible for high global warming potential and ozone depletion potential, which makes themalmost, banned everywhere. The refrigerants used in this work are eco-friendly and have insignificant Ozone Depletion Potential (ODP) and Global Warming Potential (GWP).

\section{LITERATURE REVIEW}

Naveen Kumar et al. [1] studied the performance of a simple Vapour Compression Refrigeration System using refrigerants R134a and Hydrocarbon (mixture of R290 \& R600a) and found that Hydrocarbon refrigerants are most suitable replacement refrigerants with respect of exergy efficiency and also in terms of GWP which is far less than R134a. Mukul Kumar et al. [2] studied the working of a simple VCRS using two different refrigerants namely R134a and Hydrocarbon. They used exergy analysis as an instrumentfor designing and performance evaluation of a VCRS. In analysis it was observed that COP and Exergy efficiency of VCRS using Hydrocarbon as a refrigerant is less than R134a. Also R134a is best according to zero ODP and low GWP have better performance than Hydrocarbon.

Niraj Kumar Mahato et al. [3] studied the working of a VCRS using two different refrigerants mainly R134a and Hydrocarbon employing two different types of condenser cooling such as air cooled and water cooled. The result shows that the refrigeration system performance gets improved in water cooled condenser with Hydrocarbon as a refrigerant. Sattar et al. [4] studied the working of a domestic refrigerator with $\mathrm{R}-134 \mathrm{a}$ as a refrigerant by replacing R-134a with Hydrocarbon. A study on condenser temperature, evaporator temperature, COP, work of compression heat rejection ratio and refrigerating effect was done. It was found that the energy consumptions were 3\% and $2 \%$ less when isobutene and butanes were used in place of R-134a in refrigerator. It was shown that the energy consumption and COP of domestic refrigerator was high when Hydrocarbons were used as arefrigerant in place of R134a. Nawaz khan et al. [5] studied an exergy analysis of a VCRS using R12, R22, and R134a as refrigerants. They developed relations to examine the total exergy destruction in the device, the overall exergetic efficiency of the device and exergy destruction ratio. 
They further formulated an equation for COP of VCRS.

Experimental results show that the COP and exergy efficiency of R12 are highercompared to that of R22 and R134a. The EDR value of R-134a is more compared to that of R-122 \& R-22. For all refrigerants,COP and exergy efficiency increases with increase in degree of sub-cooling.

Nawaz Khan et al. [6] studied the working of VCRS for four different configurations with four different refrigerants. The four configurations were simple VCRS multiple VCRS with flash chamber, multiple VCRS with water inter cooler and liquid sub-cooler and multiple VCRS with flash intercooler and multiple expansion valve. The four refrigerants were R-12,R-134a,R-407 and R-717. It was found that the refrigerant R717 has highest COP for simple VCRS, multiple compression system with flash chamber and MCRS with flash intercooling \&multiple expression valve followed by the R12 in simple VCRS, R134a in MCRS with flash chamber and R407 in MCRS with flash intercooling and multi expression valve but in MCRS with water intercooler and liquid sub-cooler the highest COP is of R12 followed by R717.

Wongwises et al. [7] studied the working of a VCRS with different refrigerants like Hydrocarbon (A mixture of Propane/Butane in ratio 60/40\%) and R134a. It was found that energy consumption was lower in the case of Hydrocarbon refrigerant than R-134a. This was due to the fact that the saturation temperature of Hydrocarbon and the latent heat of vaporization of Hydrocarbon are better than that of R-134a. So this causes less energy destruction and suitable for replacement of R-134a on the basis of $2^{\text {nd }}$ law efficiency.

Selladurai et al. [8] studied the working of a domestic VCRS with refrigerants R-134a and R290/R600a. It was found that R290/R600a mixture showed higher COP and exergy efficiency than R-134a. It was also found in their observations that the maximum irreversibility was in compressor compared to condenser, throttling device and evaporator.

MastaniJoybari et al. [9] studied the working of a domestic VCRS designed to use 145g of R134a as a refrigerant. The refrigerant R134a was substituted by R600a and $60 \mathrm{~g}$ of R600a showed same result as in the case of $145 \mathrm{~g}$ of R134a. The result showed that how Hydrocarbon mixtures are advantageous from economical point of view and reduces the risk of inflammability.

Baskaran et al. [10] studied the working of a VCRS with various eco-friendly refrigerants. The performance was compared on the basis of COP, pressure ratio and environmental aspects such as ODP and GWP. It was noted that R-170 is most suitable alternative for R-1324a. The COP of the deviceenhances with rise in temperature of evaporator while keeping temperature of condenser as constant.

Reddy et al. [11] studied the working of a VCRS with refrigerants R134a, R143a, R152a, R404a, R407c, R502 and R507a using numerical analysis. The impact of variation of evaporator temperature, degree of sub-cooling at condenser temperature on COP and exergy efficiency is discussed. It was found that the temperature of condenser and evaporator have significant effect on COP as well as on energetic

efficiency. They also found that the performance of R-134a was better in all aspects while it was poor for R407c.

Bolaji et al. [12] studied the working of a VCRS with refrigerants R12, R134a and R152a. It was found that R152a refrigerant best suited for a substitution of R134a.

Bilal et al. [13] examined the performance degradation of a VCRS due to fouling for various applications. Two sets of refrigerants such as R-134a \& R410a, R-407c \& R-717 and R-404a \&R-290 were taken depending upon the assumption and their properties.

\section{SYSTEM DESCRIPTION}

In vapour compression refrigeration system fundamental processes such as isentropic compression, isobaric condensation, isenthalpic expansion and isobaric evaporation are completed in a cycle. For this, major components of the VCR System are:
I. Compressor
II. Condenser
III. Throttling device
IV. Evaporator

At state ' 1 ', the refrigerant enters the compressor in vapour form at low temperature and pressure. Here it gets condensed at constant entropy and afterwards its temperature and pressure increase substantially to state ' 2 '. After leaving the compressor, refrigerant in vapour form goes to the "condenser" and it gets condensed into high pressure liquid inside the condenser and therefore its temperature decreases to state ' 3 ' where condensed liquid is collected in a "receiver tank". From receiver tank it enters the "throttling device" where it goes through throttling process at constant enthalpy which results to a lower pressure and its temperature is also decreased and reached to state ' 4 '. After passing through throttling device, it finally enters to "evaporator" where it gains heat from the surrounding or circulating fluid used for refrigeration purpose and vaporizes at low pressure vapour (state ' 1 ').

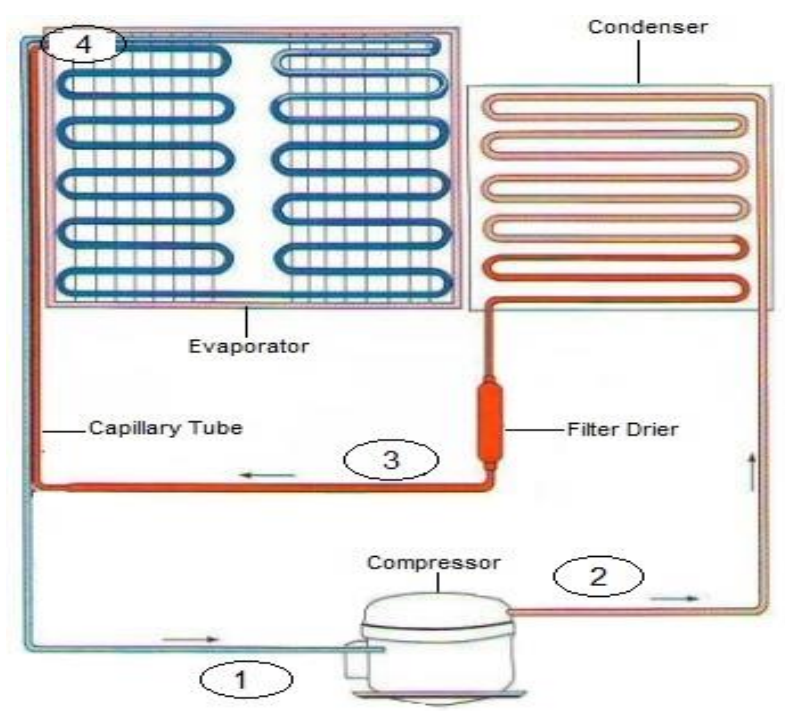

Fig.1: Flow diagram of VCRS. 


\section{PROPERTIES OF REFRIGERANT}

These properties are used for exergy analysis:-

Table I:Properties of Refrigerant

\begin{tabular}{|c|c|c|c|c|}
\hline S.NO & Property & R-134a & R-290 & R-600a \\
\hline \multirow{2}{*}{1} & \multirow{2}{*}{$\begin{array}{l}\text { Chemical } \\
\text { formula }\end{array}$} & $\begin{array}{c}\text { Tetrafluor } \\
\text { oethane }\end{array}$ & Propane & Is obutane \\
\hline & & $\mathrm{CH}_{2} \mathrm{FCF}_{3}$ & $\begin{array}{c}\mathrm{CH}_{3} \mathrm{CH}_{2} \mathrm{C} \\
\mathrm{H}_{3}\end{array}$ & $\begin{array}{c}\left(\mathrm{CH}_{3}\right)_{2} \mathrm{CH} \\
\mathrm{CHF}_{3}\end{array}$ \\
\hline 2 & $\begin{array}{c}\text { Molar } \\
\text { Mass } \\
\text { (kg/K-mol) }\end{array}$ & 102.03 & 44.9 & 58.12 \\
\hline 3 & 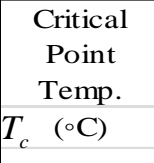 & 101.06 & 96.67 & 134.98 \\
\hline 4 & $\begin{array}{c}\text { Critical } \\
\text { Pressure } \\
P_{c} \text { (bar) }\end{array}$ & 40.593 & 4.24 & 3.66 \\
\hline 5 & $\begin{array}{c}\text { Critical } \\
\text { Density } \\
\left(\mathrm{Kg} / \mathrm{m}^{3}\right)\end{array}$ & 511.9 & 220 & 221 \\
\hline 6 & $\begin{array}{c}\text { Boiling } \\
\text { Point }\end{array}$ & -26.074 & -42.2 & -11.8 \\
\hline 7 & ODP & 0 & 0 & 0 \\
\hline 8 & GWP & 1430 & & 3 \\
\hline
\end{tabular}

\section{THERMODYNAMICS OF VCRS}

A. The exergy analysis is based on following assumptions:

1. We assume that dead state temperature $\left(\mathrm{T}_{0}\right)$ is atmospheric temperature.

2. Adiabatic or mechanical efficiency of the compressor is about $100 \%$.

3. In this system dead state enthalpy $\left(\mathrm{h}_{0}\right)$ and dead state entropy $\left(\mathrm{S}_{\mathrm{o}}\right)$ have been found with reference to the dead state temperature $\left(\mathrm{T}_{0}\right)$.

4. Kinetic and potential energy in the system is insignificant.

5. Expansion process in the expansion valve or throttle valve is carried out at constant enthalpy.

6. Pressure loss in pipeline of the system is negligible.

7. For finding the value of enthalpy, entropy etc, steady state operation is considered.

8. Refrigerants are eco-friendly in terms of GWP and ODP.

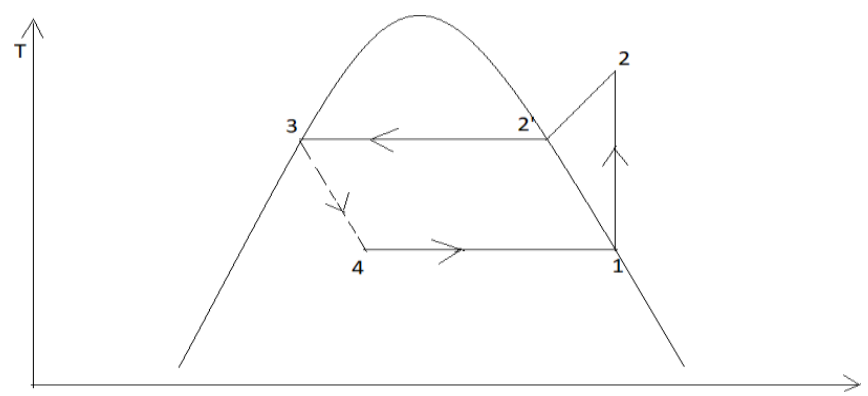

B. Temperature and entropy diagram of a VCR system

Fig.2: T-S Diagram of VCRS

\section{C. $\quad$ Pressure and enthalpy diagram of a VCR system}

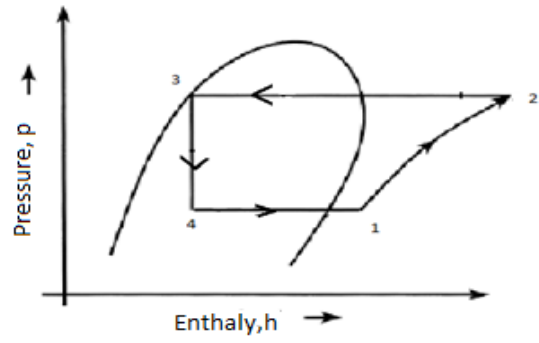

Fig.3- P-h diagram of VCRS

In thisdiagram,

Process 1-2 Compression process at constant Entropy

Process 2-3 Isobaric heat rejection

Process 3-4 Expansion process at constant Enthalpy

Process 4-1 Isobaric heat addition

$$
\begin{gathered}
\text { C.O.P }=\frac{Q_{E}}{W_{C}} \\
\text { C.O.P }=\frac{h_{1}-h_{4}}{h_{2}-h_{1}}=\frac{h_{1}-h_{3}}{h_{2}-h_{1}}
\end{gathered}
$$

\section{Exergy analysis of a VCRS}

Exergy is the thermal property which indicates the maximum potential work that the reversible system will do until it reaches the local thermodynamic equilibrium. Exergy analysis or availability is used to assess the efficiency of a thermodynamic process. Although exergy is not conserved, they may be destructed when we use the experimental data for finding the exergy loss from the tests using refrigerants R-134a and Hydrocarbon for finding qualitative measurement of the system irreversibility. For a system, component wise exergy balance equation is:-

(a) For compressor :

Compressor work,

$W_{C}=m_{r}\left(h_{2}-h_{1}\right)$

Exergy at inlet, $\lambda_{1}=m_{r}\left(h_{1}-T_{0} S_{1}\right)+W_{c}$

Exergy at outlet, $\lambda_{2}=m_{r}\left(h_{2}-T_{0} S_{2}\right)$

Exergy loss in the compressor can be calculated as,

$\mathrm{I}_{\text {Comp. }}=\mathrm{m}_{\mathrm{r}}\left(\mathrm{h}_{1}-\mathrm{T}_{\mathrm{o}} \mathrm{S}_{1}\right)-\mathrm{m}_{\mathrm{r}}\left(\mathrm{h}_{2}-\mathrm{T}_{0} \mathrm{~S}_{2}\right)+\mathrm{m}_{\mathrm{r}}\left(\mathrm{h}_{2}-\mathrm{h}_{1}\right)$. . .

(b) For condenser :

Heat rejected at constant pressure in condenser can be calculated as,

$Q_{\text {cond. }}=m_{r}\left(h_{2}-h_{3}\right)$

Exergy at inlet, $\lambda_{2}=m_{r}\left(h_{2}-T_{0} S_{2}\right)$

Exergy at outlet, $\hbar_{3}=m_{r}\left(h_{3}-T_{0} S_{3}\right)$

Total exergy loss in condenser,

$I_{\text {cond. }}=m_{r}\left(h_{2}-T_{0} S_{2}\right)-m_{r}\left(h_{3}-T_{0} S_{3}\right)-Q_{\text {cond. }}\left(1-\frac{T_{0}}{T_{3}}\right)$ 
(c) For expansion valve :

Enthalpy is constant during expansion process ,

So, $h_{3}=h_{4}$

Exergy at inlet, $\lambda_{3}=m_{r}\left(h_{3}-T_{0} S_{3}\right)$

Exergy at outlet, $\lambda_{4}=m_{r}\left(h_{4}-T_{0} S_{4}\right)$

Total exergy loss in expansion,

$I_{\text {exp. }}=m_{r}\left(h_{3}-T_{0} S_{3}\right)-m_{r}\left(h_{4}-T_{0} S_{4}\right)$

$h_{3}=h_{4}$

$I_{\text {exp. }}=m_{r} T_{0}\left(S_{4}-S_{3}\right)$

(d) For evaporator

Heat addition at constant pressure in evaporator, $Q_{\text {eva. }}=m_{r}\left(h_{1}-h_{4}\right)$

Exergy at inlet, $\lambda_{4}=m_{r}\left(h_{4}-T_{0} S_{4}\right)+Q_{\text {eva. }}\left(1-\frac{T_{0}}{T_{4}}\right)$

Exergy at outlet, $\lambda_{1}=m_{r}\left(h_{4}-T_{0} S\right)$

Total Exergy loss in evaporator,

$I_{\text {eva. }}=m_{r}\left(h_{4}-T_{0} S_{4}\right)+Q_{\text {eva. }}\left(1-\frac{T_{0}}{T_{4}}\right)-m_{r}\left(h_{1}-T_{0} S_{1}\right)$

(5)

Overall exergy loss of the system

$I_{\text {Total }}=I_{\text {comp. }}+I_{\text {cond. }}+I_{\text {exp. }}+I_{\text {eva. }}$

Exergy Destruction (ED) in the system:

For each component of the system, exergy destruction can be calculated as:-

Exergy destruction in compressor,

$E_{\text {dcomp. }}=E_{\lambda 1}+W-E_{\lambda 2}$

$E_{\text {dcomp. }}=m_{r}\left(T_{0}\left(S_{2}-S_{1}\right)\right)$

Exergy destruction in condenser

$E_{\text {dcond. }}=E_{\hbar 2}-E_{\hbar 3}$

$E_{\text {dcond. }}=m_{r}\left(h_{2}-T_{0} S_{2}\right)-m_{r}\left(h_{3}-T_{0} S_{3}\right)-Q_{c}\left(1-\frac{T_{0}}{T_{3}}\right)$

Exergy destruction in throttle valve,

$E_{\text {dthrottle }}=E_{\lambda 3}-E_{\lambda 4}$

$E_{\text {dthrotte }}=m_{r}\left(h_{3}-T_{0} S_{3}\right)-m_{r}\left(h_{4}-T_{0} S_{4}\right)$

Exergy destruction in Evaporator ,

$E_{d e}=E_{\lambda 4}+Q_{e}\left(1-\frac{T_{0}}{T_{4}}\right)-E_{\lambda_{1}}$

$E_{d e}=m_{r}\left(h_{4}-T_{0} S_{4}\right)+Q_{E}\left(1-\frac{T_{0}}{T_{4}}\right)-m_{r}\left(h_{1}-T_{0} S_{1}\right)$

Total Exergy Destruction,

$\sum E_{d}=E_{\text {de }}+E_{\text {dcomp. }}+E_{\text {dcond. }}+E_{\text {dthrottle }}$

Exergetic efficiency,

$\eta_{\text {exergy }}=\frac{Q_{e}}{W_{c}}\left(1-\frac{T_{0}}{T_{e}}\right)$

Exergy Destruction Ratio (EDR) :

Exergy Destruction Ratio is defined as the ratio of the overall exergy destruction in the system to the exergy in the product and it can be calculated by -
$E D R=\frac{E D_{\text {Total }}}{E P}$

EDR related to the exergetic efficiency given as:-

$E D R=\frac{1}{\eta_{\text {Exergy }}}-1=\frac{E D_{\text {Total }}}{E P}$

Exergy in the product is given as,

$E D_{\text {Total }} \times \eta_{\text {Exergy }}=E P\left(1-\eta_{\text {Exergy }}\right)$

$E P=\frac{E D_{\text {Total }} \times \eta_{\text {Exergy }}}{\left(1-\eta_{\text {Exergy }}\right)}$

\section{RESULT}

The following graph is drawn corresponding to different evaporator temperature with the help of SigmaPlot software. These graphs show the comparison of VCRS using refrigerant R134a with that using Hydrocarbon refrigerant on different parameters such as Exergy Efficiency, COP, EDR and Irreversibility.

Graph of Exergy efficiency vs temperature

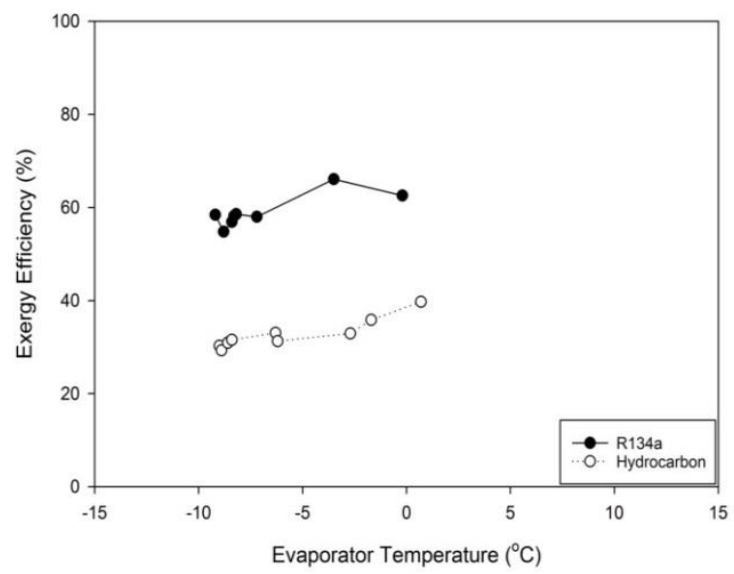

Fig 4: Evaporator temp. and Exergy efficiency

Graph of Actual COP vs Evaporator temp.

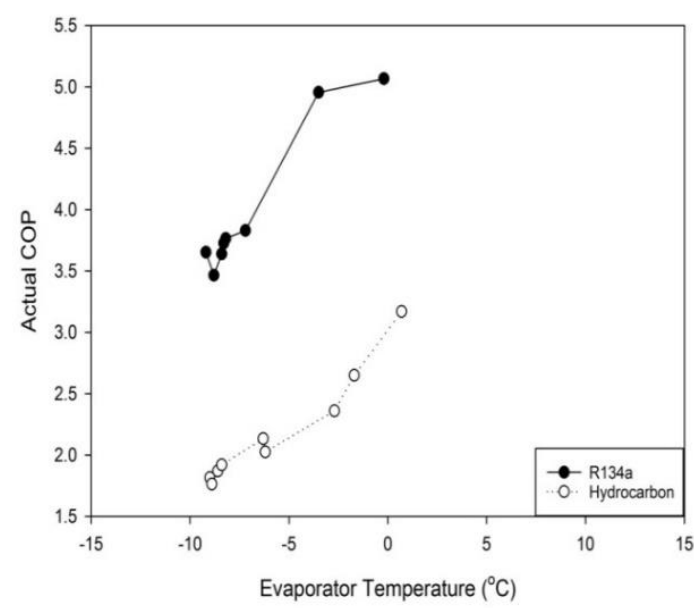

Fig 5: Evaporator temp.and Actual COP

Published By: 
Graph of EDR vs Evaporator temp.

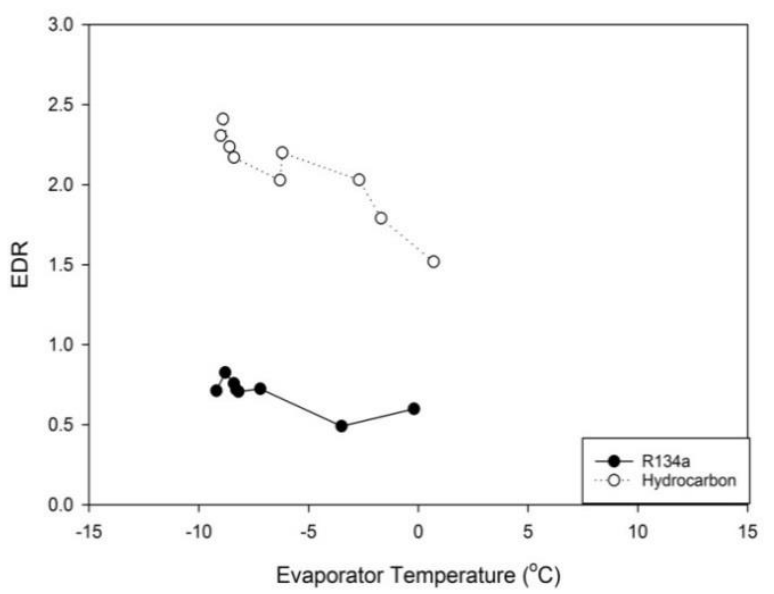

Fig 6: Evaporator temp. and Exergy destruction Ratio Graph of Irreversibility vs Evaporator temp.

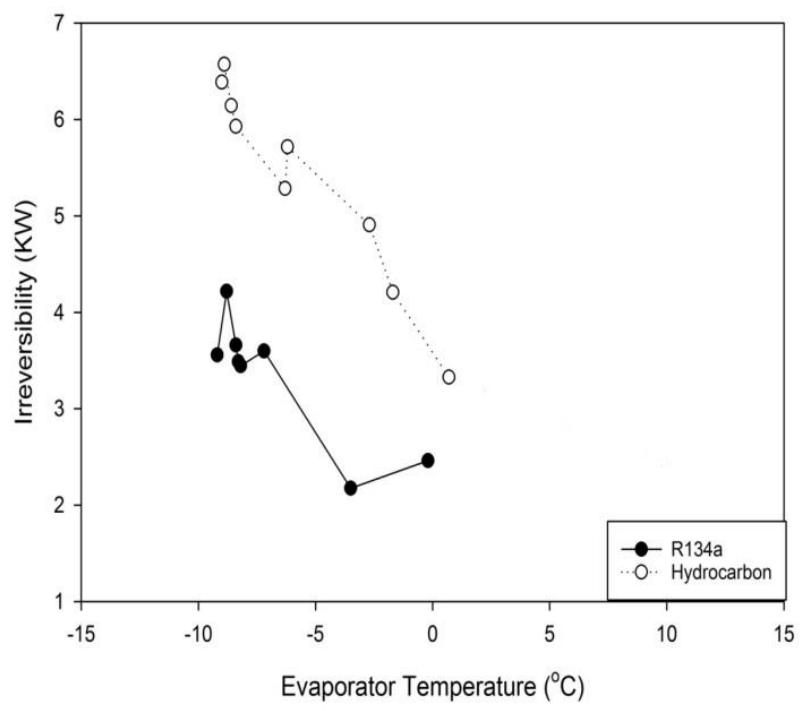

Fig 7: Evaporator temp. and Total Irreversibility

\section{CONCLUSIONS}

The following points are concluded from the above exergy analysis

- $\quad$ The second law efficiency (Exergy efficiency) and first law efficiency (COP) of VCR system underHydrocarbon refrigerant is less than that of VCR system using refrigerant R134a.

- R134a is advised to use in general as it is easily available in the market. It has II $^{\text {nd }}$ law efficiency higher than Hydrocarbon (mixture of R290 \& R600a).

- When using refrigerant R134a, maximum irreversibility is seen in throttling device followed by condenser and evaporator. Whereas in case of VCR system using Hydrocarbon (mixture of R290 \& R600a), maximum irreversibility is seen in condenser followed by throttling device and evaporator.
- As the temperature of evaporator decreases, the measure of total irreversibility increases and it was found that the hydrocarbon refrigerant (mixture of R290 \& R600a) has the maximum value of total irreversibility.

The first law efficiency of VCR system decreases as the temperature of evaporator decreases and this decrease is more seen in the case of Hydrocarbon refrigerant.

\section{NOMENCLATURE}

$\mathrm{T}_{1}$ Compressor inlet temperature $\left({ }^{\circ} \mathrm{C}\right)$

$\mathrm{T}_{2}$ Compressor exit temperature $\left({ }^{\circ} \mathrm{C}\right)$

$\mathrm{T}_{3}$ Condenser exit temperature $\left({ }^{\circ} \mathrm{C}\right)$

$\mathrm{T}_{4}$ Evaporator inlet temperature $\left({ }^{\circ} \mathrm{C}\right)$

$\mathrm{T}_{\mathrm{o}}$ Dead state temperature $\left({ }^{\circ} \mathrm{C}\right)$

hEnthalpy $(\mathrm{kJ} / \mathrm{kg})$

$\mathrm{h}_{1}$ Specific enthalpy atinlet of compressor $(\mathrm{kJ} / \mathrm{kg})$

$\mathrm{h}_{2}$ Specific enthalpy at exit of compressor $(\mathrm{kJ} / \mathrm{kg})$

$\mathrm{h}_{3}$ Specific enthalpy atexit of condenser $(\mathrm{kJ} / \mathrm{kg})$

$\mathrm{h}_{4}$ Specific enthalpy at inlet of evaporator $(\mathrm{kJ} / \mathrm{kg})$

SEntropy (kJ/kg-K)

$\mathrm{S}_{0}$ Entropy at dead state $(\mathrm{kJ} / \mathrm{kg}-\mathrm{K})$

$\mathrm{S}_{1}$ Specific entropy at inlet of compressor $(\mathrm{kJ} / \mathrm{kg}-\mathrm{K})$

$\mathrm{S}_{2}$ Specific entropy at exit of compressor $(\mathrm{kJ} / \mathrm{kg}-\mathrm{K})$

$\mathrm{S}_{3}$ Specific entropy at condenser exit $(\mathrm{kJ} / \mathrm{kg}-\mathrm{K})$

$\mathrm{S}_{4}$ Specific entropy at evaporator inlet $(\mathrm{kJ} / \mathrm{kg}-\mathrm{K})$

$\mathrm{m}_{\mathrm{r}} \quad$ Mass flow rate of refrigerant $(\mathrm{Kg})$

COP Co-efficient of Performance

$\mathrm{QE}_{\mathrm{E}} \quad$ Refrigerating effect $(\mathrm{kJ} / \mathrm{S})$

$\mathrm{W}_{\mathrm{C}}$ Compressor work (KW)

I Exergy loss

$\mathrm{E}_{\mathrm{d}} \quad$ Exergy destruction $(\mathrm{kW})$

$\eta_{\text {exergy }}$ Exergy Efficiency

EDR Exergy Destruction Ratio

ED $_{\text {total }}$ Total Exergy Destruction

EP Exergy in the product

VCRSVapor Compression Refrigeration System

MCRS Multiple Compression Refrigeration System

GWP Global Warming Potential

ODPOzone Depletion Potential

$\lambda$ Exergy

\section{REFERENCES}

1. Naveen Kumar, Munna Rajak and Dhiraj Jha(2019) "Exergy analysis of VCR System working with refrigerants R134a \& Hydrocarbon", "IJREAM Volume-05, Issue-02, May 2019, P.P-747-753.

2. Mukul Kumar and R.K. Nayak (2018) "Exergy Analysis of Vapour Compression Refrigeration System Using R-134a and Hydrocarbon as Refrigerants", IJREAM Vol.-04,ISSN: 2454-9150.

3. Niraj Kumar Mahato and Dhiraj Jha (2017) "Comparison of performance of VCRS with different modes of condenser cooling with different refrigerants", ICETETSM-17,Vol-6,Issue No.07,pp. 293-298.

4. M. A. Sattar, R. Saidur and H. H. Masjuki (June-2016), "Performance Investigation of Domestic Refrigerator Using Pure Hydrocarbons", IJSER International Journal of Scientific \& Engineering Research, Volume 7, Issue 6.

5. Md. N. Khan, M. Khan, Md. Ashar, A.Zafar Khan (2015) "Energy and Exergy Analysis of Vapour Compression Refrigeration System with R12, R22, R134a", International Journal of Emerging Technology and Advanced Engineering, Vol-5, Issue No.03, pp.210-216. 
6. Md. Nawaz Khan, Md. Atif and Md. Ashar, (2014), "A Comparative study of refrigerants for simple and compound compression with flash chamber at high compression ratio", VSRD Int. Journal of Mech, Civil, Automobile and Prod Engineering, Vol. IV Issue IX.

7. Wongwises, V.Selladurai, (2013) "Exergy analysis of a domestic refrigerator using eco-friendly R290, R744, R404a refrigerant mixture as an alternative to R134a", Journal of Thermal Analysis and Calorimetry.

8. R. Saravanakumar, V. Selladurai,(2013) "Exergy analysis of a domestic refrigerator using eco-friendly R290/R600a refrigerant mixture as an alternative to R134a",Journal of Thermal Analysis and Calorimetry.

9. Md. M Joybari, Md. S Hatamipour, Amir Rahimi, F G Modarres (2013), "Exergy analysis and optimization of R600a as a replacement of R134a in a domestic refrigerator system". IJR, Vol-36, pp.12331242.

10. Baskaran A, Mathews P.K (2012), "A performance comparison of Vapour Compression Refrigeration System using eco-friendly refrigerants of low global warming potential", IJSRP, Volume 2, Issue 9, ISSN 2250- 3153, P.P: 1-8.

11. V. S. Reddy, N. L Panwar, S. C Kaushik,(2012) "Exergy analysis of a vapour compression refrigeration system with R134a, R143a, R152a, R404a, R407c, R410a, R502 and R507a”, Clean Technologies and Environmental Policy.

12. B. O. Bolaji, M. A. Akintunde, T. O. Falade(2011), "Comparative analysis of performance of three ozone-friends HFC refrigerants in a vapor compression refrigerator", IJSEE, Vol-2, pp.61-64.

13. B.A. Qureshi and S M Zubair,(2011) "Performance degradation of a Vapour Compression Refrigeration System under fouled conditions", IJR,Vol-34, pp.1016-1027.

\section{AUTHORS PROFILE}

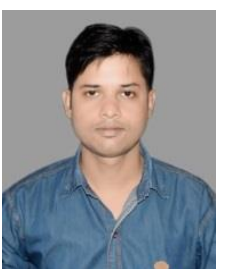

Naveen Kumar, M.Tech student in Mechanical Engineering, BIT Sindri, Dhanbad, India. He did his Bachelor of Engineering in Mechanical Engineering from B.I.T. Mesra, Ranchi, India. He is currently working in the field of Refrigeration and air conditioning and published his review paper in International Journal for Research in Engineering Application \& Management (IJREAM).

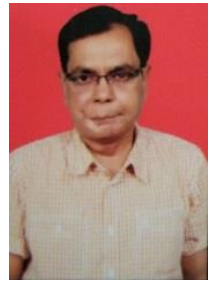

Dhiraj Jha, Assistant professor, Department of Mechanical Engineering, BIT Sindri, Dhanbad, India. He is a member of various professional bodies like IEI and ISTE. He did his BE and ME in mechanical Engineering from BIT Mesra, Ranchi, India. His area of research is energy and energy conversion, conservation, its management. etc. Presently he is working in the field of refrigeration and airconditioning for environmental issue. 